\title{
A POÉTICA DE JOSÉ CARLOS LIMEIRA: A HERANÇA DO SAGRADO
}

\author{
Zoraide Portela Silva*
}

RESUMO: Este artigo tem o objetivo central de apresentar o papel desempenhado pela herança do sagrado na configuração de alguns poemas do escritor contemporâneo afro-brasileiro José Carlos Limeira - exemplo maior da geração de escritores militantes negros que começaram a produzir na década de setenta do século XX. A análise de sua obra poética visa a construção das identidades afrobrasileiras que se formam através dos "lugares da memória" construídos de modo a evidenciar as especificidades de um espaço da "margem" que busca ressaltar as marcas de suas heranças africanas e torná-las produtivas para o seu projeto político-literário.

PALAVRAS-CHAVE: Limeira; Poesia afro-brasileira; Religião; Identidade.

É que a reinterpretação brasileira (quando não colonial) do legado simbólico africano sempre foi, predominantemente, ético-religiosa e, mais raramente politica. Quando consegue,por intermédio de elaboração intelectivas e afirmativas, a tradição negra insere-se historicamente na formação social brasileira para oferecer em termos éticos ou religiosos, outra cosmovisão da vicissitude civilizatória do escravo e seus descendentes. (Muniz Sodré)

A epígrafe acima com que inicio esse artigo é, na verdade, uma pista de meu percurso de leitura, sem no entanto, deixar de indicar aspectos significativos da poesia de José Carlos Limeira, constantemente destacados pela crítica à sua obra, e aos quais não poderei

\footnotetext{
* Doutora em Estudos Comparados de Literaturas de Língua Portuguesa pela Universidade de São Paulo (Usp). Professora Adjunta da Universidade do Estado da Bahia (Uneb). Integrante das linhas de pesquisa de Ensino, Linguagens e Identidades no PPGELS - Programa de Pós-graduação em Ensino, Linguagem e Sociedade da Uneb.
} 
escapar. Refiro-me claramente aos aspectos da herança do sagrado afro-brasileiro aí presentes, especificamente o "Candomblé". Assim, o leitor habituado a trilhar sua produção poética e capaz de identificar, nas palavras de Sodré, a origem - o texto Pensar nagô (2002) - perceberá que o elemento inicial a mobilizar minhas reflexões está diretamente relacionado à questão da construção de novos caminhos no cenário da poesia negro contemporânea do sagrado como elemento da preservação das memórias e tradições do povo afrobrasileiro em que, segundo o mesmo autor, “(...) pelo sentir do corpo, o homem não está somente no mundo, mas este está nele” (SODRÉ, 2002, p. 106).

A ratificação de Sodré estabelece uma referência sobre a trajetória do escritor negro contemporâneo José Carlos Limeira que traçarei brevemente, já que sua atuação como escritor e os caminhos que decidiu trilhar estão vinculados à situação da exclusão e da violência do sujeito negro que teve a sua história sequestrada ao longo do processo de colonização do país. Ou seja, a sua poética está ligada ao desnudamento da realidade social de exclusão e marginalização de uma população de negros e negras brasileiros.

José Carlos Limeira é um poeta negro baiano em cuja obra encontramos uma persistência em torno das manifestações culturais populares, das experiências históricas, da afirmação da identidade, da violência contra as mulheres negras, do genocídio negro,do resgate das memórias e tradições das comunidades negras (protesto, resistência, sabedoria, religiosidade). Todas essas formas de expressividade resultam, como aponta o crítico e poeta Edmilson de Almeida Pereira, na "particularidade do ser negro para contrapor-se à espoliação imposta aos afrodescendentes" e a sua voz representa, deste modo, "a voz da coletividade especifica com a qual se identifica” (PEREIRA, 2015, p. 141).

Nascido na cidade de Salvador, em 1 o de maio de 1951, Limeira pertence a uma família de Cachoeira, recôncavo baiano. Educou-se em ambiente culturalmente hibridizado. Seu conhecimento de religião afro-brasileira deu-se não apenas pela experiência pessoal, mas, sobretudo, através da pesquisa. Limeira ingressa na Sociedade Acadêmica Naval, no Rio de Janeiro, em 1969. Nesse período conheceu a poesia e, a partir dela, formou seu 
imaginário. A poesia foi a grande herança da mãe, que "fazia poesia, falava poesia" e que fez da vida um belo poema escrito de garra, dedicação e carinho (LIMEIRA, 1984, p. 73).

Começa a se interessar pelo estudo da religião afro-brasileira. Seu acesso aos rituais afro-brasileiros ocorreu de duas maneiras: por um lado, através da vivência pessoal, relatada em muitos de seus textos; por outro, como parte de um projeto de preservação da cultura dos seus ascendentes. Consequentemente, o discurso de Limeira parte de um lugar enunciativo de sua cultura. Em entrevista, ele afirma:

Eu hoje tenho uma relação muito próxima com a Ialorixá que é a mais antiga do culto do Jeje-Mahin na Bahia. Seu nome é Gaiacu Luiza e ela instalou um terreiro em Cachoeira. Ela é oriunda da Roça de Ventura, que é a mais antiga casa de culto Jeje-Mahin do Brasil.[...]

A minha mãe, ao mesmo tempo que era catolicíssima, dedicava-se também ao candomblé. O ostensório da Igreja da Lapinha ${ }^{1}$, por exemplo, foi ela quem presenteou.[...] ela tinha um assentamento pelas imagens da roça de Luiza e cuidava das imagens.[...]

$\mathrm{Eu}$ nunca estive tão longe quanto desejavam, porque, mesmo quando estava no Rio, eu visitava candomblés, estudava candomblé e escrevia sobre candomblé. Eu tinha objetivos já determinados no candomblé. Eu o via também como fator decisivo de preservação de costumes, cultura, ritos, comportamentos e dignidade do negro no Brasil. Porque foi o candomblé o grande mantenedor de nossas tradições. [...] o candomblé é vital para mim, enquanto alicerce estruturador do meu ser negro dentro deste universo, permitindo-me o aprendizado do respeito, da tradição, do aprendizado da música, da língua e a reprodução de uma cultura milenar importantíssima para o ser humano. ${ }^{2}$

Por essas razões, a poesia de José Carlos Limeira busca construir uma identidade que possa ser reconhecida também através dos "lugares da memória", segundo a expressão de Pierre Nora (1993), para quem os "lugares da memória são antes de tudo, os restos", que têm que ser arquivados, materializados a serviço de uma história que marca o luto da

${ }^{1}$ Igreja Matriz da paróquia da Lapinha, localizada no bairro do mesmo nome, em Salvador.

${ }^{2}$ Entrevista concedida à autora deste artigo em julho de 2003, em Salvador, no gabinete do poeta. Daqui em diante referida como Entrevista com o Autor, ou, preferencialmente, EA. 
"memória viva". Os lugares onde a memória cristaliza-se e refugia-se estão ligados a este momento particular de nossa história, como, por exemplo, a luta originada nos quilombos, a preservação das memórias e tradições religiosas do povo afro-brasileiro, a estética negra.

\section{A poética da resistência pelo sagrado}

A produção de mulheres negras e de homens negros como Conceição Evaristo, Esmeralda Ribeiro, Livia Natalia, Cidinha da Silva, Rita Santana, Cristiane Sobral, Elizandra Souza, Cuti, Lande Onawale, Ele Semog, José Carlos Limeira e outras e outros, trazem para a cena reflexões sobre os sucessivos processos de expropriações dos quais os negros foram vítimas. Refiro às mais variadas formas de expropriação, desde aquelas relacionadas à economia (trabalho escravo, proletarização), até às relacionadas ao mundo do saber e da cultura. "Também formulam questões para uma nova ordem de maior auto-estima, tolerância e solidariedade”. (CUTI, 2002 p. 34). Isso porque, as textualidades afro-brasileiras sempre foram articuladas a partir de embates e negociações.

É fato evidente, nas textualidades afro-brasileiras, que a mitologia dos orixás constitui um processo de resistência a partir do qual muitos escritores se inspiram para reconstruir e recompor os pedaços do seu passado. "Um largo espectro do milenar conhecimento das antigas civilizações africanas veio trazido pelos escravos para o 'novo mundo' e transmitida aos descendentes." (AUGEL, 1997, p. 189). Até hoje, em muitos templos afrobrasileiros, existe a metafórica representação de um navio de madeira pendurado ou fixado na entrada das casas de culto. Lembra-nos Paul Gilroy de que os navios eram elementos móveis que representavam os espaços de mudança entre os lugares fixos que conectavam:

Eles eram algo mais - um meio para conduzir a discussão política, e, talvez, um modo de produção cultural distinto [...]. Os navios também nos reportam a Midlle Passage, a micropolítica semilembrada do tráfico de escravos e sua relação tanto com a industrialização quanto com a modernidade. Por todas essas razões, o navio é o primeiro dos cronotopos modernos pressupostos por minhas tentativas de repensar a modernidade por meio da história do Atlântico Negro e da diáspora africana do hemisfério ocidental. (GILROY, 2001, p. 60) 
A herança cultural dos símbolos sagrados e da lembrança coletiva criou um espaço religioso, mítico, social e mesmo político para o afro-brasileiro. A preservação do culto dos antepassados e da crença nas divindades integrantes da cosmogonia religiosa das regiões, sobretudo da África Ocidental, foi e continua a ser um elemento essencial para a autoidentificação do afro-brasileiro. Há um excelente estudo de Muniz Sodré (2002) em que ele ressalta a importância da dimensão do espaço para a prática religiosa, tanto para o indivíduo isolado como para a comunidade, lembrando o papel representado pelo "território", pelo espaço como uma condição necessária para a formulação da identidade de um grupo.

As linhas de relacionamento identitárias eram retraçadas, na Bahia e em outros espaços, através dos rituais afro-brasileiros. Segundo Muniz Sodré (2002), os africanos usavam colares feitos de búzios (rosário de Ifá) e de contas coloridas como forma de apontar pertencimentos e devoções religiosas. Sem dúvida, José Carlos Limeira, ao longo dos anos e em meio a sua poética de resistência, apresenta elementos de referências ao universo jejeiorubano, fortalecendo o sentido de pertencimento a um princípio fundador, assim a sua textualidade parte de muitos elementos do candomblé, como danças rituais, os ritos iniciáticos, os textos sagrados, personagens, histórias e musicalidade. A poética de Limeira resgata o sentido das religiões afro-brasileiras, não só no sentido de homenageá-las, mas, principalmente, no combate ao racismo cultural-religioso que se manifesta material e simbolicamente, ratificando continuamente preconceitos, estigmas e estereótipos, ou seja, "oferecer em termos éticos ou religiosos, outra cosmovisão da vicissitude civilizatória do escravo e seus descendentes" (SODRÉ, 2002, p. 172). No poema "Traços" Limeira enfatiza as tradições religiosas e o contexto sagrado afro-brasileiro:

Carrego comigo os traços

Sonhos dos oprimidos

Contas e adereços

Que falam de muitos sentidos

Que contam dos nossos feitiços

Que mostram certos endereços

Entre o sim e o não do que há

Dos nossos maiores acertos 
No branco de Oxalá

De Ogum ostento o azul

Uso de todas as cores

Do vermelho e rouge de Exu

Aos colares de laguidbá

Minhas contas de coral, Âmbar e louça

Vão do verde de Oxossi

Ao ouro da Oxum mais moça

(Negras intenções, p. 37-38)

Nos versos acima, o sujeito poético ressalta o pertencimento e a relação dos negros com os Orixás através do espaço preservado pelo terreiro, assim, "no interior da configuração simbólica dos nagôs o corpo humano é permeável a mundo histórico e cosmo mítico, exibindo ritualisticamente esta sua singularidade" (SODRÉ, 2002, p. 121). Também presta homenagem a Exu, que, no panteão dos deuses africanos, é considerado uma força motora, detentor da força, do axé, é quem pode abrir os caminhos, respeitando uma ordem ritual, muito embora possa, igualmente, travá-los, pois é o habitante e senhor das encruzilhadas. Desse modo, nas comunidades litúrgicas dos cultos afro-brasileiros, os terreiros servem, exemplarmente, para ilustrar o papel que representa a base territorial para a continuidade cultural dos antigos escravos e seus descendentes.

Nos seguintes versos, "Digam o que quiserem/Eu sou de um povo de fibra/Que resiste ao que der e vier /[...]/Sou desse povo de Santo/E se quiser outro tanto/Sou mesmo é do Candomblé" (2000, p. 37-38). O poeta parece sugerir que o contexto sagrado afrobrasileiro funcionou e funciona como uma forma de resistência. Refiro-me as formas de resistência relacionadas às várias manifestações de intolerância religiosa assistida pela sociedade, como invasões a terreiros, violência contra o povo-de-santo, quebra dos símbolos afro-brasileiros. É sabido que, após a emancipação jurídica dos escravos em fins do século passado, a elite branca dominante, diante da necessidade de garantir a sujeição social negra e com vistas a dar continuidade à exploração, procurava negar ao negro qualquer espécie de autonomia. A religião católica foi imposta como um mecanismo de controle ideológico. Tal postura chega ao século XX, quando as instituições das religiões negras são perseguidas 
e proibidas no Brasil. Segundo Anamaria Morales:

Impedidos de bater seus atabaques, os terreiros mal podiam realizar os rituais, que envolvem a música e a dança característica de cada orixá. [...] a suspensão de tal proibição se deu oficialmente em 1938 pela pena do Presidente Getúlio Vargas, [...]. Mas o fim da obrigatoriedade de registro de terreiros na Delegacia de Jogos e Costumes, a qual cabia autorizar as cerimônias, só se deu na Bahia durante o governo de Roberto Santos em 1976 (MORALES, 1988, p. 268).

A legislação brasileira procurava determinar locais e momentos nos quais seriam permitidos ao afro-brasileiro circular pelos espaços urbanos e, mais que isso, deixar evidente que a abolição não lhe outorgava direitos de cidadão comum. Segundo Florentina de Souza (2000), do mesmo modo que persistia quase invisível das figurações do perfil nacional, o negro deveria permanecer invisível e ausente de certos espaços sociais exclusivamente destinados aos "brancos". A invisibilidade do afro-brasileiro adquire formatos variados na vida pública e privada, nos setores econômicos e político-sociais do país.

As proibições dos cultos motivaram várias tentativas de soluções negociadas, buscadas na "proteção" de elementos dos grupos prestigiados ou ainda mediante o pagamento de taxas de licença de funcionamento. A população de Salvador criou, ao longo do tempo, formas de resistência ao esmagamento cultural e político que sempre a ameaçou. Nos períodos colonial e imperial, quando as irmandades religiosas baianas se constituíam em poderosas organizações de ajuda mútua e de identidade social, as confrarias de negros eram das mais importantes, como, por exemplo, a Irmandade de Nossa Senhora do Rosário dos Pretos, estabelecida em 1646, localizada na Igreja de Nossa Senhora do Rosário, no Pelourinho. Estas Irmandades, além das suas funções normais de confraria religiosa católica, serviam também de elemento definidor de identidade e preservação da cultura negra, ao incluir em suas festividades elementos oriundos das culturas africanas, promover empréstimos para aquisição de alforria, prestar assistência em casos de doença e de morte etc.

Se, como afirma Bacelar (1989, p. 33), a construção de uma identidade étnica é um jogo de permutas, manipulações e estratégias de diferenças e semelhanças diante de uma 
etnia dominante, podemos pensar que o negro da Bahia colonial, além de oferecer resistência, fazia, também, contestação, denúncia da realidade da escravidão, do sofrimento e da morte, através das irmandades leigas. A própria nomenclatura atribuída às irmandades, representa a situação e as necessidades do negro escravo, através da apropriação da mítica cristã. Nosso Senhor Bom Jesus da Paciência, Nosso Senhor Bom Jesus dos Martírios dos Jeje, Nossa Senhora do Rosário dos Pretos e Nossa Senhora da Boa Morte são alguns exemplos.

A atuação das primeiras Irmãs da Boa Morte teve importância política, social e, significativamente, religiosa. Segundo Pierre Verger (1987), foi como organização advinda das mulheres adeptas a confraria Nossa Senhora da Boa Morte que teria sido fundada, no início do século XIX, o primeiro Candomblé Keto de Salvador. A partir de 1820, a Irmandade teria se expandido para a cidade de Cachoeira, local onde ainda hoje preserva seus rituais tanto públicos quanto secretos.

Já no poema “Águas do Paraguassu”, o sujeito poético evoca as águas do velho Paraguassu, associando-as a "espelhos" e "luzes profundas", detentoras do mistério das deusas Kayalas e Dandalundas, orixás que representam as águas. Nesse sentido, este poema assume uma função emblemática no que diz respeito ao simbolismo das águas nas liturgias do candomblé. Compreende-se, ao ler o poema, que o poeta apresenta as divindades e as suas atribuições, por exemplo as Dandalundas, são representantes da nação Angola e Oxum para a nação Nagô, é a deusa das águas doces, do ouro, que carrega consigo predicados da beleza e da vaidade:

As águas do velho Paraguassu

São Abebes, espelhos, luzes profundas

Donde emergem perfeitas, belas

Kayalas e Dandalundas

E vão todas elas ao RumpaymeAyonoRuntoloji

No fim da tarde, quando é mais suave a brisa

Para conversar, sem alarde, com Gaiacu Luíza.

Bênçãos em todas as línguas, todas as estradas

Ewe, Fon, Gun, Quimbundo, Ioruba, Mahi,

Quicongo

Umbundo 
E nos faz atrevidos...

Sabemos vodunces, iaôs, muzenzas

Em todos os sentidos

Iansã é oyá, Dandalunda é Oxum

Xangô e Sobô, Jeje é Nagô

Angola é Ijexá

(CN 25, p. 94-96)

Este poema, que tem como título inspirado no nome de um rio muito importante no Recôncavo baiano, o "Rio Paraguassu", já apontava na textualidade a preocupação do poeta com a imagem simbólica das águas como uma grande metáfora da purificação, indicando a limpeza, a remissão, a perfeição que caracterizam as cerimônias do candomblé, com uma série de iniciações, “abertas àqueles que são chamados pelos deuses, qualquer que seja sua origem étnica, e à medida que se vai penetrando no interior do santuário que os mistérios vão sendo aprendidos.” (BASTIDE, 2001, p. 25). As águas, vistas como purificação ritual de culto e de conexão com as entidades e as energias do cosmos, bem como local de iniciação mítico-mística, configuram-se, ainda, como espaço de renascença e transformação ${ }^{3}$.Para o poeta, "As águas do Velho Paraguassu” são:

Testemunha de tantas magias

Lavam-me de tantas mágoas, águas de alegrias

Fazem renascer em cada um de nós

Guerreiros, Rainhas, amantes, Feiticeiros

Mães e Filhos de Santos.

(CN 25, p. 94-96)

O poeta assume a criação artística e resgata a identidade quando registra, pela via literária, o mito de Oxum, patrimônio cultural africano, como forma de reflexão do projeto de elaboração de outros perfis identitários e de uma memória histórica em relação às práticas ancestrais e aos rituais vivenciados pelo povo africano. Por outro lado, a referência ao

${ }^{3}$ Cf. Chevalier, as significações simbólicas da água podem reduzir-se a três temas dominantes: fonte de vida, meio de purificação, centro de regenerescência. Esses três temas se encontram nas mais antigas tradições e formam as mais variadas combinações imaginárias - e as mais coerentes também. 
mito de Oxum, em todo o poema, poderia ser apontada como libertação, símbolo da vida, purificação, fecundidade. Além disso, como bem ressalta Eduardo Fonseca Junior:

Conta-se que quando os Orixás chegaram à Terra, costumavam reunir-se sem a presença das mulheres. Aborrecida por não poder participar das deliberações, Oxum preparou sua vingança, trazendo a esterilidade às mulheres, e impedindo que os objetivos dos deuses fossem alcançados. Os Orixás buscaram então a ajuda de Oludumaré; que explicou a eles que, sem a presença de Oxum, nada poderia dar certo. Dengosa, ela demorou a aceitar o convite dos Orixás para que participasse das reuniões, mas finalmente concordou, e a fecundidade voltou. (FONSECA Jr., 1995. p. 119)

A elaboração simbólica do mito de Oxum no corpus literário possui uma tradição que perpassa inúmeros textos de poetas brasileiros. Importante lembrar que quando se fala do culto a Oxum no Brasil, fala-se de uma divindade originária de uma região específica da Nigéria, África, onde reina um rio do mesmo nome, também ligada a fecundidade. Assim, além das dimensões plurais do poder de Oxum, no sentido maternal, politico, também representa a libertação para a condição feminina.

Vale lembrar o poder de outra imagem - "Gaiacu Luiza" -, grande sacerdotisa, guardiã da fé e da tradição africana, conhecedora da história das ancestrais femininas, também focalizada anteriormente, da qual Limeira explora o confessional ao longo da sua obra poética, através da representação da grande liderança feminina do terreiro "RumpayameAyonoRuntoloji”, localizado no Recôncavo baiano, em Cachoeira, centro afro-religioso muito importante no Brasil, que já serviu de diálogo e inspiração de poetas e ficcionistas que criaram suas obras a partir da complexidade ritual do candomblé.

Nas religiões da África negra e nos cultos afro-brasileiros a mulher ocupa um lugar destacado como doadora da vida, guardiã principal e transmissora das tradições religiosas e culturais, sendo laço que liga o Sagrado com a vida biológica e espiritual, por ser a zeladora da matéria mítica que modelou o ori de cada pessoa (TEODORO, 1996, p. 70).

Teodoro ressalta a importância das sacerdotisas no envoltório religioso dos cultos 
afros, evidenciando como o espaço-terreiro e os corpos interpenetram simbolicamente. No poema “Águas do Paraguassu” Limeira aponta para a importância da figura feminina na preservação da religião e cultura negra. Foram mulheres negras que, em meados do século XIX, estabeleceram e dirigiram, escondidas das autoridades, as cerimônias religiosas africanas que ficariam conhecidas, quando puderam ser celebradas livremente, como candomblé. "Este grupo de mulheres de aparência católica praticante eram, ao mesmo tempo, as fiéis guardiãs dos cultos dos nagô-ioruba" (MOTT, 1988, p. 38).

Nos terreiros, essas mulheres constroem um tempo mítico e um espaço sagrado, cujo traço de africanidade recria um novo lugar para a comunidade. Desta forma,

conhecer a história destas ancestrais femininas, reconhecendo-as como atravessadoras de fronteiras, traz às mulheres negras de hoje, a possibilidade de contato com uma dimensão da religião que seita nenhuma traz: a aceitação da complexidade do seu humano (EGYDIO; OLIVEIRA, 1993).

Assim, a reflexão do poeta sobre a representação simbólica das águas e da figura feminina nos rituais sagrados se reproduz ao longo poema, pois a água torna-se, nesse sentido, o espaço iniciático da vitalidade, que sagra "Guerreiros, Rainhas, amantes, Feiticeiros/ Mães e Filhos de Santos” para a luta e preservação dos laços por meio das práticas religiosas, antes interditadas pela Igreja Católica, irrompe, agora livre, no imaginário literário, trazendo novas formas de alargar as fronteiras que se manifestam na linguagem mitopoética do poema. Nos Ritos de Saída e Comunhão, a água serve para lavar o colar e, muitas vezes, a cabeça (moradia do orixá) e também o corpo inteiro. Nessa cerimônia da lavagem, o indivíduo, que a ela se submete, fica ligado a um mundo diferente, está preso a toda uma cadeia de obrigações negativas ou positivas, de encargos e de deveres. Para o poeta, as águas são elementos de proteção nas religiões da tradição africana e, nesse sentido, receber a proteção das águas, "lavar-se colar, ori e corpo", pode ser pensado como o início da conquista dos sonhos, afirmando, assim, não só a identidade negra afro-brasileira dilacerada por tantas interdições, mas também como a dimensão social se revela por meio da linguagem poética: 
As águas porque são águas, fluidos sem tormentas

Dançam entre otás as danças dos ventos

Os ventos aos sopros, todos abraços

Entram pelo ori, chamados pelos toques

Vivos em seus passos de Angola, Ketu, Jeje, Nagô

Inquices de qualquer nação

Somos, pois, um só povo

Para aprender todos os toques em todos os cantos

E queremos ver-nos dançando

Em todos os terreiros, para todos os santos

E vamos além deste sonho menino

Fazer o mais correto pelas Águas que protegem

Das dores, desatinos, e nos preparam, nos regem

Para viver todo Rito, celebrar o planeta e a vida

Cumprindo nossos destinos.

(CN 25, p. 94-96)

No poema seguinte, "Benta de Oxalá, Bene de Xangô", o poeta ressalta nitidamente imagens da afirmação da religião afro-brasileira. Toda a simbologia dos citados orixás reverbera no poema, emitindo sons e significados que ressoam na cultura afro-brasileira. As palavras da língua iorubá, com sua acentuação oxítona, proporcionam ao poema uma forte vocalização. Lançando mão do conceito mais sagrado da religião afro-brasileira que é o axé, força vital, força divina nos homens e nas coisas, realiza um jogo lúdico de palavras contando as façanhas e as características dessa divindade:

Ilê, Axé

Xangô é de Obá

Na calunga de Paiê

Viu nascer dia, e o chicote fustiga

$\mathrm{Na}$ carne de Benta carapinha

Nega de Oxalá

E Bene nego de briga

Axé, Oxalá, Xangô

(Arco-íris negro, p. 29)

Nos versos acima, o sujeito poético, ao tempo em que narra uma situação envolvendo a "nega Benta" e "Bene nego de briga", registra a imbricada relação entre negros e deuses africanos. Benta é de Oxalá, assim como Bene é de Axé, Oxalá e Xangô. O poema 
não apenas relata a proteção dos orixás, mas também denuncia a situação de opressão e castigo a que os negros são submetidos ("Viu nascer dia e o chicote fustigar/ na carne de Benta carapinha"). Nesse sentido, a herança do sagrado tem papel fundamental, uma vez que parece funcionar como forma de alento para a situação que "Benta" se encontra: fustigada com chicote. Os versos "Nega de Oxalá/ E Bene nego de briga/ Axé, Oxalá, Xangô" não somente enumeram divindades do candomblé, mas, principalmente, trata-se de um processo de reelaboração da linguagem.

As atividades da mulher Yorubá, ainda na África, eram de grande importância ao lado de seu companheiro. Podemos assegurar que essas mulheres no Brasil, antes da Abolição e mesmo depois dela, "quando os negros foram alijados da nova ordem econômica que se instaurara com o mercado do trabalho livre" (FERNANDES, 1964, p. 14), passaram a exercer papéis de manutenção da família em termos socioeconômicos e culturais. Comparadas aos homens negros, as mulheres encontravam realmente melhores condições de sobrevivência, trabalhando como lavadeiras, amas, cozinheiras, ou vendendo seus quitutes pelas ruas. Muitas vezes chegaram a comprar a alforria de seus companheiros. Foram elas, também, guardiãs da fé e da tradição africana, conhecedoras da história das ancestrais femininas, as primeiras a abrirem terreiros e a assumirem papéis de importância na hierarquia religiosa.

Na poética limeiriana, as mães-de-santo têm reconhecida sua atuação não somente como liderança, mas, principalmente, como voz dinâmica na transmissão, criação e recriação cotidiana das tradições porque suas histórias nos remetem ao passado, à memória histórico-religiosa afro-brasileira como fonte de inspiração, ação e mudança no futuro. Nesse sentido, o texto poético, mediador da memória sócio-religiosa dos terreiros, constitui universo de representações e significações não apenas do lugar da mulher na religião do candomblé, mas, sobretudo, da sua importância na construção de espaços abertos, terreiros, onde a liberdade de ser está garantida a todos, independentemente de sexo, etnia ou cultura.

O poeta, armado com o instrumento do verbo, tem em vista o esforço comum de emancipação social, econômica e também psicológica da mulher negra e do homem negro 
no Brasil. Assim, descreve, com detalhes, alguns locais sagrados e personagens dos rituais dos terreiros de candomblé. Cabe ressaltar, ainda, que esses rituais são parte e instrumento de um processo de conscientização e resgate não só da memória cultural, mas, sobretudo, ética, que tem suas raízes sentimentais e históricas no passado africano. Ou seja, essa é a senda percorrida pelo poeta José Carlos Limeira para potencializar o caminho simbólico da herança sagrada, pois revela que é possível uma aproximação de um rico repertório de mitos, crenças e tradições para compreender as estratégias da manutenção da memória e da identidade decorrentes dos signos dispersos causados pela diáspora negra sobre os povos africanos. Segundo Muniz Sodré (2002, p. 133), a reposição cultural negra manteve intactas formas essenciais de diferença simbólica, como a iniciação, o culto dos mortos, entre outros, capazes de acomodar tanto conteúdo da ordem tradicional africana (orixás, ancestrais ilustres, eguns, narrativas míticas, danças etc.) como aqueles reelaborados ou amalgamados em territórios brasileiros.

\title{
JOSÉ CARLOS LIMEIRA'S POETICS: THE SACRED HERITAGE
}

\begin{abstract}
This paper has the central objective of presenting the role played by the inheritance of the sacred in the configuration of some poems by the contemporary Afro-Brazilian writer, José Carlos Limeira - a major example of the generation of black militant writers who began to produce in the seventies of the $20^{\text {th }}$ century. The analysis of Limeira's poetic works seeks to construct the AfroBrazilian identities that are formed through the so called "places of memory" constructed in order to make evident the specifications of a space of "margin." This space seeks to project the marks of the writer's African heritages, and to make them productive for his political and literary project.
\end{abstract}

KEYWORDS: Limeira; Afro-Brazilian poetry; Religion; Identity.

\section{REFERÊNCIAS}

AUGEL, Moema Parente. A imagem da África na poesia afro-brasileira contemporânea. In: Afro-Ásia. Salvador: CEAO/UFBa, n. 19-20, p. 183-199, 1997.

ALENCASTRO, Luiz Felipe de. O trato dos viventes: Formação do Brasil no Atlântico Sul. São Paulo: Companhia das Letras, 2000.

BACELAR, Jéferson. Etnicidade: ser negro em Salvador.Salvador: Ianamá; Programa de 
Estudos do Negro na Bahia (Penba), 1989.

BASTIDE, Roger.. O Candomblé da Babia. São Paulo: Companhia das Letras, 2001.

CADERNOS NEGROS. (CN) 23. Poemas afro-brasileiros (Orgs. Esmeralda Ribeiro e Márcia Barbosa). São Paulo: Quilombhoje, 2000.

CADERNOS NEGROS. (CN) 25. Poemas Afro-Brasileiros (Org. Esmeralda Ribeiro e Marcio Barbosa). São Paulo: Quilombhoje, 2002. P. 94-96

CUTI, Luis Silva. O leitor e o texto afro-brasileiro. In: FIGUEIREDO, Maria do Carmo Lanna; FONSECA, Maria Nazareth Soares (Orgs.). Poéticas afro-brasileiras. Belo Horizonte: Mazza: PUC Minas, 2002.

EGYDIO, Sylvia; OLIVEIRA, KinsanR. de. Negras da diáspora: todo o poder para as Ayabas. Revista Vozes, Petrópolis, 4, 1993.

FERNANDES, Florestan, A integração do negro na sociedade de classes. Rio de Janeiro: Centro de Pesquisas Educacionais, Instituto de Estudos Pedagógicos, Ministério da Educação e Cultura, 1964.

FONSECA Jr., Eduardo. Dicionário antológico da cultura afro-brasileira. São Paulo: Maltese, 1995.

GILROY, Paul.O Atlântico negro: modernidade e dupla consciência. São Paulo/Rio de Janeiro: Ed. 34/Centro de Estudos Afro-Asiáticos, Universidade Candido Mendes, 2001.

HALL. Stuart. Da diáspora: Identidades e mediações culturais. Belo Horizonte: Ed. UFMG; Brasília: Representação da UNESCO no Brasil, 2003.

JOAQUIM, Maria Salete. O papel da liderança religiosa feminina na construção da identidade negra. Rio de Janeiro: Pallas; São Paulo: EDUC, 2001.

LIMEIRA. José Carlos. Atabaques (poesia). Rio de Janeiro: Ed. dos autores, 1984. . Negras Intenções (poesia). Rio de janeiro: Ed. dos autores, 2003.

LODY, Raul. O povo do santo: religião, historia e cultura dos orixás, voduns, inquices e caboclos. Rio de Janeiro: Pallas, 1995.

MOTT, Maria Lúcia de Barros. Submissão e resistência: a mulher na luta contra a escravidão. São Paulo: Contexto, 1988.

MORALES, Anamaria. O Afoxé Filhos de Gandhi pede paz. In:REIS, João José (Org.).Escravidão \& invenção da liberdade. São Paulo: Brasiliense, 1988.

NORA, Pierre. Entre memória e história: A problemática dos lugares. In:Revista Projeto História. São Paulo, (10) dez. 1993.

PEREIRA, Edmilson de Almeida. Da responsabilidade com a poesia. In: Limeira, José 
Carlos. Encantadas. Organizado por Guellwar Adún, José Henrique de Freitas Santos, Lívia Natália, Mel Adún. Salvador: Editora Ogum’s Toques Negros, 2015, pp. 131-136.

RODRIGUÉ, Maria das Graças de Santana. OríApéré Ó. O ritual das águas de Oxalá. São Paulo: Summus, 2001.

SODRÉ, Muniz. O terreiro e a cidade: a forma social negra e brasileira.Rio de Janeiro: Imago. Salvador: Fundação Cultural do Estado da Bahia, 2002.

SOUZA, Florentina. Contra correntes. Afro-descendência em Cadernos Negros e jornal do MNU. 2000. Tese (Doutorado) - UFMG, Belo Horizonte, pós-lit.

THEODORO, Helena. Mito e Espiritualidade: mulheres negras. Rio de janeiro: Pallas, 1996.

VERGER, Pierre. Fluxo e refluxo do tráfico de escravos entre o Golfo do Benin e a Babia de Todos os Santos dos séculos XVII ao XIX. São Paulo: Corrupio, 1987.

Recebido em: 16/10/2018.

Aprovado em: 04/02/2019. 